\title{
Teknik Belirlenimci Medya Kültürü Bağlamında Dijital Gerçeklik-Veri- Anlam İlişkisi Üzerine Epistemik Bir Tartışma
}

\author{
Hüseyin Köse, \\ Prof. Dr. \\ Atatürk Üniversitesi Illetişim Fakültesi \\ huseyink180@yahoo.com \\ ORCID: 0000-0001-5697-9009
}

\section{An Epistemic Discussion on the Relationship Between Digital Reality-Data-Meaning in the Context of Technological Determinist Media Culture}

\begin{abstract}
The concept of data, especially digital data, has created a vital transformation in the context of media culture. The critical analysis of the transformation in digital media culture undoubtedly requires that the view of technological determinism be discussed. In this context, the first striking point is that digital data is far from reflecting the cumulative nature of social reality and human experience, since collective existence is not a phenomenon to be simply absorbed via data. Today's digital culture narrative is a social / cultural formation dominated by the quantitative and does not provide a concrete clue about who we really are. The main dilemma in statistical evaluations is that they by no means have such adequate depth to surround the qualitative accumulation law. All these judgments presume an irreducible difference between data and meaning. Many predictions, associated with the relationship among information technologies/ information-meaning/ experience, from the concept of "quantified self" critiqued by Byung-Chul Han to Baudrillard's determination of "hyperreality", Neil Postman's definition of "Technopoly" to Boyd and Crawford's critique of big data, all point towards this direction. Data growth has always improved at the expense of meaning. This study aims to focus on the main concepts and debates brought up by the authors and thinkers on the theoretical plane in the context of information technologies-digital culture criticism.
\end{abstract}

Keywords: Data, digital culture, meaning, experience, information technologies

DOI:10.16878/gsuilet.829438 


\section{Une discussion épistemique sur la relation réalité numérique- données-signification dans le contexte de la culture médiatique déterministe technique}

\section{Résumé}

Le concept de données, en particulier les données numériques, a créé une transformation vitale dans le contexte de la culture médiatique. L'analyse critique de la transformation de la culture des médias numériques nécessite sans aucun doute d'ouvrir la discussion la vue déterministe technologique. Le premier point frappant dans ce contexte est que les données numériques sont loin de refléter la réalité sociale et la nature cumulative de l'expérience humaine ; parce que l'existence collective n'est pas un phénomène simple que l'on peut saisir à travers les données. La narration de la culture numérique d'aujourd'hui est une formation sociale / culturelle dominée par le quantitatif et ne fournit pas un indice concret de qui nous sommes vraiment. Le principal dilemme des évaluations statistiques est qu'elles ne sont pas suffisamment profondes pour englober la loi d'accumulation qualitative, etc. Tous ces jugements supposent une différence irréductible entre les données et le sens. Du concept de "soi quantifié " que Byung-Chul Han critique à la détermination de Jean Baudrillard de "I'hyper réalité ", de la définition "Technopoly" de Neil Postman aux critiques de grandes données de Boyd et de Crawford, c'est essentiellement ce que rapportent de nombreuses prévisions des technologies de l'information / connaissances-sens / expérience: La croissance des données s'est toujours améliorée au détriment de la perte de sens. Cette étude se concentrera sur les principaux concepts et discussions soulevés par les auteurs et les penseurs sur le plan théorique avec l'accent sur les technologies de l'information-critique de la culture numérique.

Mots-clés : Données, culture numérique, sens, expérience, technologies de l'information 


\section{Öz}

Veri, özellikle de dijital veri kavramı medya kültürü bağlamında hayati bir dönüşüm yaratmıştır. Dijital medya kültüründeki dönüşümün eleştirel analizi, kuşkusuz teknolojik belirlenimci görüşü tartışmaya açmayı gerektirir. Bu bağlamda ilk dikkat çekici husus, dijital verinin toplumsal gerçeklik ve beşeri deneyimin kümülatif niteliğini yansıtmaktan uzak oluşudur; zira kolektif varoluş, veriler üzerinden kavranabilecek yalınlıkta bir olgu değildir. Günümüz dijital kültür anlatısı nicelin hâkim olduğu bir toplumsal/kültürel biçimlenme olup, gerçekte bizim kim olduğumuza ilişkin somut bir ipucu sunmamaktadır. Istatistiksel değerlendirmelerin temel açmazı, nitel birikim yasasını kuşatacak derinlikte olmamasıdır, vb. Tüm bu yargılar, veri ve anlam arasında indirgenemez bir fark olduğunu varsayar. Byung-Chul Han'ın kritiğini yaptığı "nicelenmiş benlik" (quantified self) kavramından Jean Baudrillard'ın "hipergerçeklik" saptamasına, Neil Postman'ın "Teknolopoli" tanımlamasından Boyd ve Crawford'un büyük veri eleştirilerine kadar enformasyon teknolojileri/bilgi-anlam/deneyim ilişkilendirmesine dair birçok öngörünün işaret ettiği şey de özünde budur: Veri artışı, anlamın gözden yitirilişi pahasına gelişme kaydetmiştir hep. Bu çalışmada, teorik düzlemde adı geçen yazar ve düşünürlerin enformasyon teknolojileri-dijital kültür kritiği odağında gündeme getirdikleri başlıca kavram ve tartışmalara odaklanılacaktır.

Anahtar Kelimeler: Veri, dijital kültür, anlam, deneyim, enformasyon teknolojileri 


\section{Giriş}

Fransız düşünür René Guénon, İkinci Dünya Savaşı'nın hemen ertesinde kaleme aldığı çarpıcı yapıtı Nicelin Egemenliği'nde, her belirlemenin bir tür sınırlandırma olduğu varsayımından hareketle, sonsuz ve tanımsız olanın nicel ve hesaplanabilir karşılıklarını sonsuzluk fikrinin anlamsal daralması olarak okur. Belirsiz olan ile sonsuz arasında kesin bir ayrım yapan Guénon, tanımsız olanın da hangi kılık altında karşımıza çıkarsa çıksın, yine de sonlu ve sadece sonlu olduğunu belirtir (2012, s.19). Guénon'a göre gerçekliğin anlamı tanımlı veya tanımsız olanda değil, sürekliliği olanda açığa çıkar ve bu hiçbir nicel ölçütle izah edilemez. Düşünür, yine aynı yerde, sanayi toplumlarının krizine eğilerek, nicelin din, bilim ve sanatlar hilafına edindiği yüksek statüyü, kısaca değeri niceliğe eşitleyen hâkim anlayışı sorunsallaştııı. Aslında düşünürün nicel üzerinden tartışmaya açtığı ve itiraz ettiği şey, derinliğin karşısında gitgide geniş bir mevzi kazanmaya başlamış olan yüzeyselliktir. Başka bir deyişle, nicel olanın maddeselliğiyle zuhur eden fenomenal dünyanın nitel olanın özle ilişkili sınırsızlığı ve sürekliliğine galebe çalmaya başlamasıdır. Bir zamanlar Antik Yunanlıların materia, modern Batı dillerinin ise substance sözcükleriyle karşıladıkları "madde", nicel ve ölçülebilir olanın değil, nitelin hedefinde yer almaktadır artık. Guénon'a göre, sonunda modern fizikçiler "niteliği niceliğe indirgemek için gösterdikleri çabalarda (...) birini diğerine karıştırma noktasına" gelmiş olup, "niteliği olduğu gibi kendilerinin 'madde' (matière) dedikleri şeye atfetmeye başlamışlardır" (2012, s.34). Bunun kaçınılmaz sonucu ise, çok geçmeden bütün hakikati maddi olanın içine yerleştirmek olmuştur. Ancak bu durum, yaşamın anlamı veya sosyal/beşeri süreçler açısından net bir şey söylememektedir bize. Zira Guénon'a göre, "her ne kadar nicelik hissedilebilir zuhurun, yani bu dünyanın temeli ise de (...), nicelik, kendi içinde değerlendirildiğinde, sadece gerekli, fakat hiçbir şey açıklamayan bir 'önvarsayım'dır" (2012, s.35-36). Dahası, niteliğin uğradığı statü kaybı, bir başka düzlemde, değerler alanında da köklü bir karmaşaya tekabül etmektedir. Guénon'un deyimiyle, "niteliğin niceliğe indirgenmesi olayı, aslında 'üstün alta indirgenmesi' olayından başka bir şey değildir" (2012, s.36).

Dijital kültürle birlikte ise niceliğin egemenliği daha da artmıştır. Bu yeni tarihsel evrede, şayet niteliğin bizatihi niceliğin bir ürünü olduğu varsayımını tespitin dışında tutacak olursak, verilerin "vermediği" şeyin ikame edici işlevini "anlam" diye yorumlamak ne derece doğrudur? Ya da dijital kültürün inkişaf ettirdiği gerçekliğin düz anlamı, verilerin yalnızca anlamsal bir boşluğa denk geldiğiyse, yokluğu var eden şeyin kendisini de başlı başına bir "veri" olarak görmek mümkün müdür? Üçüncü olarak, dijital enformasyon teknolojilerinin ürünü olan enformasyon ve veri kavramlarının geçip giden zamana karşı gösterdiği/gösterebildiği direncin gücü ve temsil ettiği hakikat değeri üstüne yeni medya kültürü bağlamında neler söylenebilir? Nasıl ki istatistik, yaşamdan mistik/mitolojik boyutu kovmuşsa, dijital verinin duyusal gerçekliği tanımlayıcı gücü de hayatın çok boyutlu katmanlarını yüzeysel bir izlenimden ibaret kılmıştır denebilir. Bu durumda verinin anlamsal boşluğu giderdiği savı son derecede tartışmalı bir konu olduğu gibi, anlatıyı kuran 
öğelerin de tamamen anlamlı şeylerden oluşması gerektiğine ilişkin muteber bir kural yoktur.

Yukarıdaki sorular dikkate alındığında, dijital veri temelli bilginin yaşamsal gerçekliği yeterince yansıtmadığına ilişkin yaygın bir kanaat vardır. Bu kanaati aynı zamanda teknolojik belirlenimcilik yaklaşımına yöneltilen, teknik ilerlemenin her zaman beraberinde toplumsal ve kültürel değerler alanında da bariz bir iyileşmeyi getirmediği eleştirisi odağında test etmek hayli ilginç sonuçlar ortaya koyabilir. Özellikle de dijital olarak kurgulanan hikâyelerin ontolojik ve deneyimsel açıdan içerdiği derin çatlakların, verinin birincil düzeyde ihtiva ettiği yüzeysel anlam adına görmezden gelinip gelinemeyeceği konusunda... Kanaatimizce teknolojiyle destekli yeni medya kültürünün ihtiva ettiği nitel düzeyin pratik hayatlarımızda üretebileceği genel hoşnutluk bakımından asıl açıklığa kavuşturulması gereken mesele de budur. Başka bir deyişle, yeni medya kültürünün dört bir koldan yaydığı ve genel olarak algıdan bilgiye salınan içeriğinin "anlamlı yaşama" düzeyimize yaptığı/yapacağı katkının etraflı bir kritiğini yapmak gerekir. Bilgi, kuşkusuz bilmenin verdiği esenliği sağlayıp insanların içinde bulundukları süreçlerin belirsizliğini azaltıcı bir işlev görür. Ancak bilgi, -salt duyu verilerinin de ötesinde- eğer felsefi düşüncenin keşfedici gücünü içermiyorsa neyi ne kadar bilmemize aracılık edebilir? Bu da, yanıtı aranacak ikinci soru olacak bu çalışmada. Gerçekten de özellikle yeni medya kültürü çağında tartışılması gereken oldukça ciddi bir sorundur bu; zira teknik anlamda sınırsız bilgi üretim kapasitesine sahip olup da bilgi meşgulü bir çağın bunca düşünme zorluğu çekmesi son derece izaha muhtaç bir konudur. Şurası bir gerçektir ki, yeni medya kültürü içinde filizlenen büyük veri fenomeni, geniş bilgi kümelerinin ölçtüğü hesaplanabilir ilişki biçimlerine odaklanır. Veri, bilmeyi, anlamayı, nüfuz etmeyi, idrak etmeyi değil, daha ziyade anlama, kavrama, idrak etme ve bilme biçimlerimize ilişkin bir hareket noktası sunar. Başka bir deyişle, veri bir varış noktası değil, öncelikle bir kalkış noktasıdır. Veriler, sözgelimi bir şeyi neden yaptığımız sorusuna yönelik net bir yanıt oluşturmazlar kesinlikle. Yine bu bağlamda, bilginin klasik anlamda şifa veren bir kaynak olduğu yargısını aşındıran da, çok miktarda ve karmaşık veri yığınının deva vermez bir tür yeni kavrayış ve ontoloji biçimi yaratmış olmasıdır. Asıl yıkıcı olan da bu tekno-kültürel zihniyetin, dijital çağın âlimi mutlak yanılmazlık kültü ve sonu gelmez nimetlerine olumlu bakanlar arasında geniş ölçekli bir uzlaşma yaratmış olmasıdır. Her yerde büyük veri saplantısına büyük teknoloji yüceltimi eşlik etmektedir. Dijital kültür ve sunduklarına koşulsuz biçimde arka çıkanlarca egemen kılınmaya çalışılan bu kibirli eğilimi ihbar edenlerce dile getirilmeye çalışılan eleştirilerin özlü ve tutarlı bir takdiminin yapılmaya çalışılacağı bu teorik tartışmada, büyük veri anlatısı, entelektüel becerilerin gözden düşüşü veya tükenişi, yaşamsal deneyim/anlam-veri ilişkisi bağlamlarında irdelenecektir. Başka bir deyişle, böyle bir irdelemeden umulan yarar, özünde, “insanların neden bir şeyler yaptığını veya yazdığını sorgulayan daha başka muteber yöntem ve eleştirilerin çok sayıda numaranın arasında kaybolup gitmesi"ni (Boyd ve Crawford, 2015, s.202-203) anlamaya çalışmaktan ibarettir. Bu çaba oldukça önemlidir, zira dijital medya çağının büyük veri anlatısının hemen her alanda ağırlığını hissettiren âlimi mutlaklığının ve matematiksel açıdan 
taşıdığı varsayılan şaşmaz kesinlik ve yanılmazlığının ontolojik hakikatlerimiz ve yaşadığımız hayatların anlam ve muhtevası üzerine verdiği vaazlar son derecede ürkütücü bir manzara arz etmeye başlamıştır. Şu halde, dijital gerçekliğin ifade ettiği anlam veya anlamları ya da verilerin "veremediklerini" tartışmaya açmadan önce, köklü toplumsal/kültürel dönüşüm süreçlerine yataklık ettiği varsayılan teknik determinist yaklaşım üzerine de özlü birkaç şey söylemek gereklidir.

\section{Teknolojik Belirlenimcilik Görüşü: Genel Bir Perspektif}

Genel kabul gören bir yaklaşıma göre, teknoloji sosyolojisi, teknolojinin evrim sürecinde üç ana aşama bulunduğunu iddia eder. İlki, teknolojinin toplumsal üretimine atıfta bulunarak, temelde tekniğin oluşum ve gelişim koşullarına odaklanır. Bu ilk aşama, ayrıca disiplinlerarasıı̆ı̆ın uzmanlık alanlarını ortak bir teknolojik hedefe dönüştürdüğünün altını çizer. Öte yandan, yine bu dönemde ağırlıklı olarak teknolojiyle ilgili yoğun tartışmalar görülür. Teknik ilerlemenin toplumsal yaşamı dönüştürücü gücünün yarattığı iyimser düşünce ve endişeler tartışmaya açıır. Kimi somut projelerde teknolojinin toplumsal yapısıyla ilgili ortaya konulan modellere göndermeler yapılır. Teknik kapasitenin zorlayıcı gücü yerleşik bakış açılarını hükümsüz kılarak yeni bakış açıları yaratır. Lajeune'e göre, bu dönem ortaya konulan görüşleri "toplumsal teknoloji modeli" şeklinde adlandırmak son derece yerinde olup, bu bakış açısından teknik ilerlemenin kendisi ağ oyuncuları arasındaki çoklu müzakerelerin ve istişarelerin bir sonucu olarak kabul edilir (Lajeune, 2015, s.38). Teknolojinin gelişiminin bir diğer evresi, epistemik, sosyolojik ve tarihsel açıdan tam bir kopuşa tanıklık eden yayıım evresidir. Bu dönemde teknoloji kendi yaratıcılarının etkisinden kaçmaya ve yeni oyuncular tarafından desteklenmeye başlar. Bu da oldukça anlaşılır bir durumdur, zira yeni teknolojiler her zaman tasarımcıların teknolojiyi yeni kullanımlara veya öngörülmeyen durumlara karşı incelemelerini sağlayan deneysel aşamalardan geçer. Nihayetinde teknoloji hedef grubun paylaştığı değerlerle tutarlı olduğunda ve algılanabilir avantajları fark edildiğinde sosyal sistemler içinde hızla yayılır. Yayılımın hiç kuşkusuz daha başka ön koşulları da vardır: Denenebilirlik, kolay anlaşılabilirlik, topluma sunacağı potansiyel fayda, var olan değerlerle uyumluluk, vb. Üçüncü aşama ise, "teknolojinin etkisi" veya "teknolojik yayılımın genişletilmiş sürekliliği" şeklinde adlandırılabilecek olan teknolojinin sosyal olarak sahiplenilmesi aşamasıdır ki, bu sonuncu evrede artık teknoloji toplumu radikal biçimde dönüştürmeye başlar. Söz konusu sahiplenilme, teknolojinin yeni kullanım alanları yaratmasına izin verildiğinde ve bu yeni kullanım biçimleri toplum tarafından kabul edildiğinde ortaya çıkar. Başka bir deyişle, ancak teknolojinin toplumsal benimsenişi faaliyetten kaynaklanan uygulamalar sayesinde mümkün olur (Lajeune, 2015, s.38-39). Sosyolojik teknoloji tarihi, kısaca özetlenen bu üç evrenin ardından yeni bir realiteyi, toplumsal hayatla ilişkisi bakımından sosyal bir belirlenimciliği de beraberinde getirir. Ne var ki, sosyal belirlenimcilik, burada teknolojik yoğunlaşmanın toplumsal bir çıktısı olarak değil, teknolojiyi teknolojik belirlenimcilikten tamamen farkı bir bakış açısından görür. Burada bir teknolojinin var olmasını ve gelişimini sağlayan şeyin ağ oyuncuları arasındaki tartışmalar, müzakereler, değişimler, istişareler 
vb. etkileşimler olduğu varsayılır. Bu teoriye göre, herhangi bir teknolojik proje, teknolojiyi tanımlamak, kullanımlarını ve etkinliğini belirlemek için bir araya gelen aktörleri tanımlar. Şu halde teknoloji, tarihe damga vurmuş bir dizi toplumsal gerçeğin sonucudur (Lejeune, 2015, s.38). Başka bir deyişle, teknolojik gelişmeler toplumsal yapıyı değil, toplumsal yapıda olup bitenler teknik ilerleme dinamiklerini belirler. Toplumsal olanın belirleyici olduğu bu görüşte, teknik ilerleme toplumsal olay ve faillerin bir ürünüdür. Bu nedenledir ki, sosyal determinizm savunucuları, teknolojinin ancak bir aktörler ağına entegre edilmesi durumunda kendisini dayatabileceğini iddia ederler. Çünkü sadece teknik ilerlemenin değil, toplumsal faillerin belirleyici etkisinden bağımsız bir tarihsel gelişmenin de varlığından söz edilemez. Dahası, toplumsal belirlenimcilik görüşüne göre, bilime teknolojik bir proje sunan asli merci bizzat toplumun kendisidir, bu nedenle teknolojinin kökeninde bilim değil, toplum vardır. Şu halde, teknoloji ve toplumun bir aradaki evrimi, teknolojik belirlenimcilik ile sosyal determinizm arasında bir orta yeri talep eder (Lejeune, 2015, s.38). Bu bakış açısına göre, âlimi mutlak bir niteliğe sahip olduğu varsayılan teknolojik belirlenimcilik görüşünün önemi zannedildiği kadar büyük değildir. Zira teknolojik determinizm görüşüne göre, teknoloji toplumsal tarihin tüm evrelerinde etkili olup, beşeri ilişkilerin teknik-bilimsel yenilik ve buluşların sosyal yaşama etkisi açısından değerlendirilmesini varsayar. Bu varsayıma göre, teknolojinin bağımsız bir hareket etme tarzı vardır ve insanlık tarihinde gözlenen tüm olay, olgu ve gelişmeler teknik ilerlemelerin mührünü taşır. "Örneğin teknik ilerlemenin, teknik üretim türlerinin veya elektronik medyanın ortaya çıkması çalışma hayatı üzerinde olduğu kadar örgütlerin yapısı ve ev yaşamının dinamikleri üzerinde de doğrudan ciddi etkiler yaratmıştır. Buradaki temel argüman, teknolojinin nesneler evreni ve sosyal varoluş karşısında bağımsız değişken olduğu ve her ikisini de nedensel bir mantıkla etkilediğidir" (Doray ve Millerand, 2019, s.66). Aynı şekilde, iş dünyasındaki değişimler de, genellikle yeni teknolojilere yer açmak için modüle edilmiş kurumsal bir tasarıma sahip teknolojiler ile iş yaşamında hâlihazırda geçerli olan değişikliklerin yönetilmesine yönelik yöntemlerin bir sentezi olarak düşünülebilir (Doray ve Millerand, 2019, s.68). Ne ki, bu görüşlerin de birçok bakımdan eleştirisi yapılabilir. İlk olarak, teknolojileri karakterize etmek için kullanılan değişkenlerin niteliği ve etkisi genellikle çok belirgin değildir. Zira benzer teknolojiler için farklı kullanımları veya örgütsel formları gözlemlediğimizde söz konusu nedensel bağın pek de net olmadığı görülür. İkinci olarak, yukarıda kısaca değinilen sosyal determinizm hipotezine yönelik üretilen teorik önermelerin birçoğu dayanaklarını teknolojilerin üretimini sorgulamalarından alır. Neo-klasik üretim döneminde teknik belirlenimciliğin etkilerini irdeleyen Bruno Tinel de, söz konusu tarihsel döneme ilişkin egemen üretim tarzları ile teknik determinizm arasında kurulan bağlantıyı mahsurlu görür. Tinel, neo-klasik ekonomik teoride teknik determinizmden çok çalışmanın kendisinin -yeni iş teorilerinin tümünü niteleyecek şekilde- genel iş süreçlerinin "kara kutu"su olarak takdim edildiğinden söz eder. Tinel, ayrıca, kara kutu imgesinin özellikle şirketin üretim işleviyle öne çıkarılan temsilinin tanımlanmasına hizmet ettiğini vurgulayarak, Marxın "üretimin gizli laboratuvarı" olarak adlandırdığı şeyin doğru bir şekilde anlaşılmasını güçleştirmek için kullanılmış olduğunu iddia eder (Tinel, 2019). Ti- 
nel'in savına göre, çalışmanın üretici -ve aynı ölçüde de emeği sömürücü- gücü, teknik üretim kapasitesinin kendisinden daha belirleyicidir. Bu bakış açısına göre, geleneksel teknik determinist yaklaşım, iki farklı kavramı birbiriyle harmanlamıştır: Üretimde kullanılan teknik (buharlı lokomotif veya elektrikli lokomotif, vb.) ve üretimin sosyal organizasyonu ve işbölümü (kim ne yapar?). Bu bakış açısı, üretim sürecinde kullanılan tekniğin doğrudan doğruya sosyal organizasyona indirgenmemesini olduğu kadar, aynı zamanda üretimin sosyal organizasyonunun en az teknik kapasite kadar önemli olduğunu ima eder.

Teknolojik belirlenimcilik görüşünün etkilerini medya alanına taşıdığımızda ise, özellikle yeni iletişim teknolojileri konusunda çalışan birçok araştırmacının aynı noktada birleştiği söylenebilir: Teknolojik determinizm tezini kabul etmek, beraberinde sosyal yeniliği inkar etmeyi getirir (Cabedoche, 2019). Oysaki şu gerçeği de göz ardı etmemek gerekir: Her iki dinamik de birbirini hem etkiler hem de birbirinden aynı ölçüde etkilenir. Teknik ilerleme, toplumsal yenilenmenin hem eyleyeni hem de sonucudur. Bu anlamda, teknik kapasite toplumsal yenileşmeyi belirlediği gibi, toplumsal değişim de teknik kapasiteye etki eder, onun kullanım alanlarını genişletir. Nitekim yakın zamanda yeni iletişim teknolojilerinin bir ürünü olan sosyal medya bu duruma örnek gösterilebilir. Tarihsel açıdan görkemli bir toplumsal/siyasal kalkışma olan "Arap Baharı"nda önemli bir rol oynayan teknolojinin, belki her şeye kadir olamamışsa da, harekete geçirilen referanslar dikkate alındığında, tekniğin belirleyici gücünün ileriye yönelik ne tür yeni perspektifler sunabileceği kolayca anlaşılmıştır. Özellikle sosyal medya, sadece toplumsal değişimin değil, toplumsal dünya olaylarına ve genel olarak nesnel evrene yönelik algı genişlemesinin de itici güçlerinden birisidir. Bu konuda daha da eskiye, köklere dönecek olursak, McLuhan'ın teknolojiye ilişkin bugün artık klasikleşmiş kabul edilen görüşlerini hatırlamak yeterlidir. McLuhan, fiziksel ortam tanımının radikal genişlemesini, her nesnenin "estetik" olabileceğini düşünen ve insanı duyum ilişkileri açısından incelemiş olan Giedion'a borçludur. Şayet bu bilgiye itibar edilecek olursa, McLuhan'ın herhangi bir nesneyi, eseri veya cihazı insan duyumu ile ilişkisi bakımından "ortam" olarak kabul ettiğini anlamak hiç de zor değildir. Kane'in de belirttiği gibi (2019), eğer herhangi bir ortam, duyumlar üzerinde belirli etkileri olan bir protezse, o halde bu etkiye maruz kalan herkes değişmeye mahkûmdur. Ayrıca, her kültürel dönem kendine özgü bir seçim ortamı sunar ki, insanın içinde yaşadığı dönemle duyusal ilişkisi devam ettiği sürece, söz konusu kültürel dönemin özelliklerinin onun üzerindeki egemenliği de varlığını sürdürür. Bu nedenledir ki, medyanın herhangi bir teknolojik dönüşümü sosyal çevreyi ve buna bağlı olarak da bireysel ve kolektif algıyı topluca dönüştürür. Bu nedenle, McLuhan'ın medyadan söz ederken zaman zaman ekoloji terimlerini kullanması boşuna değildir. Sonuç olarak, "ortamın önemliliği, koşullu içerikten önce gelir" (Kane, 2019). Şurası bir gerçektir ki, Innis'yan ve McLuhan'yan önermeler, iletişimin toplumsal tarihini oluşturmaya olanak sunan kültürelci iletişim kuramları içinde yer alırlar. Bununla birlikte, her iki düşünür arasındaki temel fark, ilkinin tarihsel nitelikleri medyaya atfetmesine karşılık, ikincisinin medyatik nitelikleri tarihsel süreçlere bağlamasında göze çarpar. Aynı şekilde, ilkinde araç veya medya tüm tarihsel gelişimin seyrini 
etkilerken, ikincisinde medya veya araç veya teknoloji insan yetilerini genişletir. Ne ki, bu genişleme, zannedildiği gibi her zaman geliştirici nitelikte olmayıp köreltici bir işleve de sahiptir. Nasıl ki teknolojik kapasite, her zaman insani duyumların kapasitesini arttırıp derinleştirmeye yetmiyorsa, medyanın olağanüstü çeşitlilikteki ve hacimlerdeki içeriği de anlamayı veya kavrayış gücünü geliştirmeye olanak sunmamaktadır. Şu halde, genel olarak teknik belirlenimciliğin, özelde ise sayısal teknolojiyle desteklenmiş medyanın algı ve anlamla ilişkisini dijital gerçeklik ve veri kavramları odağında değerlendirmek yararlı açılımlar sağlayabilir.

\section{Dijital Gerçekliğin Anlamı ya da Verinin "Veremedikleri"}

Anlam ve deneyim kavramları, muhtevaları salt bir veri veya bilgi parçasına indirgenemeyecek kadar derinlikli çağrışımlara sahiptir. Korku, hislenme, sevme, anlama, inanma, vb. duygulanım ve itkilerin derecesi ve şiddetini ölçmek konusunda elimizde güvenilir ölçütler ve değişmez reçeteler yoktur. Aynı şekilde, bugüne kadar dikkat yoğunluğunu mükemmelen ölçen bir cihaz icat edilmediği gibi, hayatın anlamına eşlik eden mutluluk ve iyimserlik gibi serinkanlı duygu durumlarının şiddetini herkes için olumlu yönde ve eşit miktarda arttırmayı sağlayacak sabit ve nesnel bir kriter de yoktur. Entelektüel beceriler de ölçüye vurulamaz ve rakamlarla ifadesi mümkün olmayan diğer birçok şey gibi, belirsizdir. Nihayetinde ölçülebilir ve ölçülemez olan şeyler vardır; mutlak nesnellik ve kesinlik iddialarının nesneler dünyasına dair söyledikleri, beşeri deneyim alanı söz konusu olduğunda hükümsüzdür. Mesele, özünde olgu-değer gerilimiyle ilgilidir ve sonsuz yorumlama kapasitesinin var olduğu yerde, verilerin açıkça "veremediği" sayısız şey vardır. Dahası, Boyd ve Crawford'un belirttikleri gibi, "neyin ölçülmesi gerektiğini tayin edecek olan tasarım seçenekleri de yine yorumlamaktan geçmektedir. Örneğin sosyal medya verileri alanında bir "veri temizleme" süreci bulunur ki, bu, hangi kalıpların ve değişkenlerin sayılacağı ve hangilerinin dikkate alınmayacağına karar vermektir" (2015, s.204). Yorumlama ve seçme, nihayetinde öznel bir süreçtir ve işlenmemiş geniş bir veri yığınının ne anlama geldiği hemen her zaman araştırmacının seçmeci bakışına tabidir. Dolayısıyla "yorum tarafıı̆ı̆ı" gibi bir kriter bile veriye öznel bir istikamet açısı kazandırmaya yeterlidir. Boyd ve Crawford'un işaret ettikleri ikinci husus, büyük verinin her zaman daha iyiyi veya doğruyu veremeyeceği tezidir. Araştırmacılara göre sözgelimi istatistiki çözümlemeler konusunda Twitter'ın durumu buna örnektir. Zira Twitter üzerine yapılan çalışmalar birbirinden farklı birçok kalıba dayandırılabilir. Yazarlara kulak verecek olursak, "ruhsal durum rutinleri, siyasal başkaldırı, medya etkinliklerine katıım, konuşmalı etkileşimler, vb." bu tür kalıplardandır (Boyd ve Crawford, 2015, s.205). Tüm bu farklı kalıplar dikkate alınarak oluşturulacak araştırma tasarımlarında Twitter'dan bilgi koparma girişimlerinin ulaşılan twitlerin kabaca erişilen sayısı üzerinden işlem yapmaya izin vermesi, incelenen konu ya da sorun üstüne incelikli sonuçlara varmayı güçleştirir. Dahası, Boyd ve Crawford'a göre, Twitter'ın, tüm insanları temsil etmediği gerçeği bir yana, "kullanıcı", "aktif kullanıcı", "katııımı" gibi kodlamaların da hangi nesnel kriterlere göre yapıldığı belli değildir (2015, s.205). Nitekim "aktif" olmanın ölçüsü nedir? Günde kaç saat çevrim içi olunca "aktif" 
olunur? Bir, iki, üç, dört, beş saat? Daha üstü? vs. Ayrıca kullanıcı dendiğinde birtakım olasııkları da dikkate almak gerekir; sözgelimi bir kullanıcının birden fazla sosyal medya hesabı olabileceği gibi, bazı sosyal medya hesapları da birden fazla kişi tarafından kullanılıyor veya yönetiliyor olabilir. Aynı şekilde, "aktif" hesap kavramı da sorunludur. Boyd ve Crawford'a göre, sözgelimi "doğrudan belirli bir kullanıcısı olmayıp otomatik içerikler üreten insansız "boot'lar bulunmaktadır" (2015, s.205). Bu tür hesaplara aktif hesaplar mı denecektir? Reel açıdan aktif olan hesaplarla bu tür hesaplar nasıl ayırt edilecektir? Bu ve benzeri belirsizlikler bir yana, Twitter veya daha başka dijital platformlardan süpürülen bilgilerin kullanıcılara ilişkin tutarlı bir anlatı oluşturabilme gücü de tartışmalıdır. Nitekim Pettman'ın da belirttiği gibi, "tekil kullanıcı ölçeğine inildiğinde, veri ne denli makro olursa, bu benlikler de o kadar matlaşmaktadır" (2018, s.23). Matlığa neden olan şey, bizzat elde edilen verilerin kesinliğidir. Zira "pazarlama makineleri 'bize' dair ne kadar fazla bilgi toplarsa, ortaya çıkan anlatının tutarlılı̆ı da o kadar az" olmaktadır, ya da ortaya çıkan "anlatı o kadar basittir ki, bize neredeyse hiçbir şey söylememektedir" (Pettman, 2018, s.23). Sosyal ve beşeri süreçleri istatistiksel olarak adlandırma eğilimi, gerçekliğe tıpkı büyük veri çıkmazına benzer biçimde kısa devre yaptırır. Bu konuda yöneltilmiş ciddi itirazlardan biri, felsefeyi güncel eğilimlerin sığlığını izah etmenin hizmetine koşan Güney Koreli yazar Byung-Chul Han'dan gelir. Han'ın tepkisi, dijital kültürün yaşamsal ve ontolojik gerçekliği nicelin yüzeysel çerçevesine indirgeyen hâkim eğilime yöneliktir. Han'a göre, dijital çağın bütününe hâkim olan "hayatın ölçülebilir ve nicelik olarak ifade edilebilir olduğu inancı" (2019a, s.67), zihin ve beden üzerine toplanan "yığın halindeki verilerin 'Ben kimim?' sorusuna cevap vermesi" (2019a, s.67), dijital olanın son derecede kör ve sınırlı doğasını da somut biçimde açığa vurur. Dahası, Han'a göre, dijital kültürün yaşamsal gerçekliği önceleyen niceliksel yaklaşımı "özneleri psikolojiden arındırarak" içlerini boşaltma işlevi görür ki, bu onun akla gelebilecek en ideolojik etkilerinden birisidir. Böylelikle bireylerin "henüz adı konmamış bir yaşam biçimi için serbest kalması" sağlanmış olur (Han, 2019a, s.84). Bir tür bağışıklık sistemi çöküşünü andıran bu serbest kalış biçimi, tam da psikolojiden arındırımış öznelerin sömürüye açık hale gelmeleri demektir. Psikolojiden arındırma işlemi, değer ve alışkanlıklara yönelik geliştirilmiş uzun süreli bir sadakati yok edici bir tüketim döngüsü biçiminde yaşanabileceği gibi, zaman zaman dijital kültürün aşırı içerik ve araç üretiminin yol açtığı bir tür duyusal körelme biçiminde de gerçekleşebilir. Zira aşırı enformasyon, hemen her zaman derinlikten yoksun bir algılama çerçevesi üretir. Han'ın dediği gibi, nasıl ki şayet "yüz, yüzeye ilişkin bir pürüzsüzlüğün" (2018, s.14) göstergelerinden biriyse, içeriğin aşırı yüklü sunumu da pekâlâ yaratııı imgelemin sakatlanması olarak yorumlanabilir. Her halükarda, enformasyonun üretim hızı, gizli bir vaat olarak zihinlerde bir türlü oluşturulamayan anlamın yok oluş hızıyla aynı sürede gerçekleştir. Gerçekten de vaziyetin vahameti tahmin edilemez boyutlardadır. Yaklaşan elektronik çağın olası rizikolarının büyük öngörücüsü, virtüel gerçeklik cinayetinin asli gurusu Jean Baudrillard'dan ilhamla söylersek, "sonunda temsil edilme yolunu kat etmeden olduğumuz gibi olma fırsatını yakaladık! Özgürlük yolunu kat etmeden istediğimizi isteme fırsatını nihayet yakaladık!" (2012, s.1099). Baudrillard'ın itirazı, tam olarak insandan 
aşınmış bir hacim yaratmaksızın zorlu yolların gerçek deneyimine metelik vermeyen tercihlerin kolaycılığınadır. Gerçeklik katmanları onu zorlayanı aşındırmaksızın kat edildiğinde, artık yolun vaat ettiği hiçbir anlamlı deneyim ve özgürlük biçimi yoktur. Bu bakış açısından, dijital olan da, derinliği parçalar halinde yüzeye yayan postmodern bir kültürün ürünüdür. Han'ın da deyimiyle, burada yüz değil, yüzey önemlidir; gerçeklik, pürüzsüz olanın gerçekliğidir. Yüksek hızın yarattığı döngü, yeni ve denenmemiş olana yönelik arzuyu seri üretim düzeneğinden geçirmeden anlamlı kılamaz hale geldiğinde, sosyal medyanın bulaşıcı etkisi, özgün olanı geliştirmeyi değil, taklidi, tekrarla oluşan aynıyı öne çıkararak yol almayı sürdürdüğünde, kaçınılmaz biçimde olacak olan da budur: Başka olanın, anlamlı olanın, farklılı duygusunun yitirilişi...

Dijital kültürün "seçmen davranışlarından tüketim alışkanlıklarına, ticaret rakamlarından kültürel eğilimlere" kadar (Ertürk, 2018, s.167) toplumsal süreçleri istatistiki veriler (tablolar, oranlar, grafikler, yüzdeler, vb.) üzerinden ele alma girişimi de aynı indirgemeci anlayışın bir dışavurumudur denilebilir. İstatistiki veriler elbette toplumsal süreçlere dair somut bir fikir verebilir, ancak toplumsal ve bireysel deneyimi aktardığı söylenemez. Özellikle de uzunca bir zamandır vekâleten yaşamaya koşullanmış bir izler-kitlenin varlığı dikkate alındığında. Baudrillard ve hiper-gerçeklik kavramından da bildiğimiz üzere, aşırı görüntü üretiminin gerçeklik duygusunun kaybına yol açmasıyla birlikte, gerçekliği deneyimlemenin pratik zemini de çökmüştür. Baudrillard, Simülakrlar ve Simülasyon isimli kitabını bu ontik soruna hasreder. Baudrillard'a göre kitle iletişim araçları, özellikle de televizyon, anlamın yok oluş hızına fazladan ivme kazandırmıştır. Çünkü seri mesaj üretimi, genel bir anlam kaybını önlemeye yetmemektedir. Başka bir deyişle, mesaj/imge üretimi o kadar otomatik ve hızlıdır ki, gerçeklik kendisine inanılmasını güçleştirmektedir artık (Baudrillard, 2005, s.115). Benzeri bir eleştiri, Byung-Chul Han'da da karşımıza çıkar; yazara göre, aşırı enformasyon hakikat eksikliğinin belirtisidir (2017, s.23). Yaşamsal deneyimi nicel verilerin gerçekliğine eşitleyen yaklaşımsa, mevzuyu Baudrillard'ın ve Han'ın tezlerinin de ötesine taşır. Verinin ne kadar büyük olursa olsun, varoluşun kümülatif tarihini asla kapsayamayacağını savunan kimi eleştirel görüşlerin varlığı bunun bir kanıtıdır. Bu bağlamda sadece deneyim ufkunu körelten hızlı mesaj aktarımı değil, yaşamsal deneyimi yansıtmaktan uzak veri anlatısı da kendisine kuşkuyla yaklaşılmasını gerektirir. Nitekim "ne kadar biricik ve özel olursa olsun, her bir deneyim günün sonunda bir Excel dosyası hücresine sığdırılması" durumu bunu örnekler (Ertürk, 2018, s.169). Şayet deneyim denilen şey yaşamsal gerçekliğin vasıtasızca algılanmasıysa, hiçbir deneyim hakikaten de bir Excel dosyası hücresine sığdırılamayacağı gibi, bir dizi yaşamsal an parçasının yeri de hiçbir şeyle doldurulamaz. Deneyimin veriye eşitlenememesi, eşsizliği, bir daha aynı biçimde tekrarlanamaz ve öngörülemez oluşu nedeniyledir. Oysa Ortega y Gasset'nin de belirttiği gibi, "hakikatler bir kere bilindiklerinde faydacı bir kabuk bağlarlar; bizleri artık hakikat olarak değil, faydalı birer reçete olarak ilgilendirirler" (2018, s.35). Aynı şekilde, deneyim de bir kez reçeteye dönüştüğünde çok geçmeden kalıplaşır ve farklı insanların benzer biçimde terennüm ettikleri bir gerçekliği yaratır. Oysa her deneyim bir farklılık 
imkânını içinde taşır; aksi halde, ne sahih ne de sahici olabilir. Dahası, reçetenin sunduğu kolaylık ve fetvacılık, iletişimin hızlıığına dalalettir ki, aslolan yavaş ve komplike olmaktır. Zira Han'ın da vurguladığı gibi, bir deneyim alanı oluşturmak ve hayatı içselleştirmek için "iletişimi yavaşlatacak olan karmaşıklığa" intiyaç vardır her zaman $(2017$, s.30). Karmaşıklığın azaldığı yerde hızlanan iletişimle birlikte ise, her tür deneyim alanı ve anlam yok olur. Çünkü "anlam, yavaştır" (Han, 2017, s.30). Anlamak için sahip olduğumuz zaman dilimi genişledikçe hayatın da birden bire berraklaştığı görülür. Zamansızlık yüzünden olay ve olgular hızlanmaz sadece, algılama yetisi de körelir. Bu işleyişin bellek süreçleri üzerindeki menfi etkisi ise mutlaktır. Çek yazar Milan Kundera'dan da bilmekteyiz ki, yavaşlayarak hatırlar, hızlanarak unuturuz her şeyi (2019). Bu anlamda hızlı veri akışı ve sürat, hiçbir surette hatırlamayı teşvik etmez, daha ziyade, olsa olsa aynının sürekliliğini pekiştirerek unutuşa zemin hazırlar. Oysa yaşanılan anları anlamlandırmak hatırlamakla başlar. Deneyimin dönüştürücü gücü de burada ortaya çıkar: $O$, yani "deneyim dönüştürür, aynının tekrarını kesintiye uğratır" (Han, 2019b, s.112). İletişimin hızı, deneyimsel bir daralmayı, deneyimin kısırlığı ise ontolojik hakikatte bir azalmayı getirir beraberinde. Çok daha genel düzeyde, Han'ı izleyerek söylersek, "hızlanma, dünyanın semantik açıdan kısırlaşmasına yol açar" (2019b, s.48). Medyanın mesaj aktarım hızı ve veri akışının yol açtığı şey de özünde budur: "Varlık boşluğunun yaşam sürecinin hızlanmasına eşlik etmesi..." (Han, 2019b, s.73). Han'ın dünyanın semantiğini kısırlaştırdığını iddia ettiği hız eleştirisi, en yıkıcı görünümünü "sahih zamansal pratikler"in yokluğu saptamasında edinir. Han'ın "sahih zamansal pratiklerin sonu" dediği şey, sürat ve hızlı hareket etmeyle doğrudan ilişkilidir. Zira "yeryüzü, üzerinde ne kadar hızı hareket edilirse o kadar daralı" (Han, 2019b, s.31). Bu anlamda aşııı hızlı veri artışı ve akışının da "yaşamı yeryüzü hakikatinden mahrum bıraktığı" aşikârdır (Han, 2019b, s.31).

Yeniden Boyd ve Crawford'un argümanlarına dönersek, dijital gerçekliğin güvenilirlik boyutuyla ilgili sorgulamayı da dikkate almak gerekir. Buna göre, internet ortamından koparılan verilerin güvenilirliği tartışmalı olup, "genellikle hem güvenilmez hem de kesinti ve kayıplara yatkındır. Bu tarz hata ve boşluklar, bir de çoklu veri kümeleri bir arada kullanıldığı anda daha da artmaktadır" (Boyd ve Crawford, 2015, s.204). Hal böyleyken, bu olumsuzluğa bir de, toplanan verileri yorumlama işini üstlenen araştırmacıların kendi yargılarıyla baş edebilmelerinin zorluğu eklenir. Aslında söz konusu zorluk yeni bir olgu da değildir; sosyal bilim araştırmalarının ezeli ve kronik sorunlarından birisidir bu; hiç kuşkusuz daha başka müşküllerle birlikte. Nitekim daha fazlası vardır; sözgelimi "bir veri kümesiyle ilgili istatiksel iddialarda bulunmak için o verinin nereden geldiğini bilmemiz de gerekir" (Boyd ve Crawford, 2015, s.204). Veri nereden gelmektedir? Kaynağın ya da ortamın meşruiyeti hakkındaki uzlaşmaya ilişkin, özellikle de ortamın dışta bıraktıkları dikkate alındığında, bu konuda ne söylenebilir? Ya da kaynağın veya ortamın meşruiyetini teyit edenlerin kimliklerinin meşruiyeti hakkında ne tür iddialar öne sürülebilir? Bir diğer sorun, belli matematiksel ölçeklere sığdırabilmek için bağlamından koparılan veriyle ilgilidir. Boyd ve Crawford'a göre, genellikle "geniş veri kümeleri modellenebilir olduğu için, veriler sıklıkla matematiksel bir mode- 
le sığacak kadar küçültüldüğünden", "bağlamının dışına çıkarılmış veri anlam ve değerini kaybeder" (2015, s.207). İletişimsel metinler üzerinden gerçekleştirilen klasik "cımbızlama" yönteminin tahripkâr etkisi burada da geçerlidir. Öncesiz ve sonrasız hükümlerin karşılık geldiği yegâne gerçeklik, yalnızca çerçevelenmiş olan üzerindeki vurguyu korur, çerçevenin tümünü ve dışını dikkate almaz. Aynı şekilde, kafalarda etkisi hesaplanmış referans çerçeveleri kurarken ayrıntılı bir sahnelemeden kaçınır, gerçekliği eksik veya çarpık aktarır veya resmeder. Yazarlara göre, özellikle de "sosyal ağ sitelerinin doğuşu 'toplumsal çizelge'de endüstri çıkışlı bir takıntıya sebep olmuştur" (2015, s.207). Bu nedenledir ki, bağlamından koparılmış veri parçalarından hareketle oluşturulmuş olan çizelgeler, insan ilişkilerinin niteliği hakkında pek bir şey söylemez bize. Dahası "insanlar arasındaki ilişkiyi bir çizelge olarak gösterebiliyor olmak, bu ilişkilerin eşit değerde bilgi taşıdığı anlamına da gelmemektedir" kesinlikle (Boyd ve Crawford, 2015, s.207). Son yıllarda "dijital" sıfatının yaygın olarak "sayısal"ın yerine kullanılmaya başlanması da, gitgide beşeri ilişkilerin ve toplumsal değerlerin niteliğinin nicel bir ölçüyle adlandırımaya çalışıması anlamına gelmektedir ki, çevremizde olup biten şeyleri anlamak ve anlamlandırmak bakımından yakın gelecekte bizi bekleyen asıl büyük riziko da budur. Dijital ile birlikte gözden yiten şey, yalnızca anlam ya da nesnel gerçeği anlamlandırma yetisi değil, Han'ın yakın zamanda kendisiyle yapılmış olan bir söyleşide belirttiği gibi, "bilgi birikimine dayalı olan tecrübe"dir (Han ile söyleşi, 07.01.2020). Han'a göre, sayısal veriler tecrübe içermezler, sadece bilgi verirler; dijital kültürün bilgiden anladığı da büyük ölçüde bilgi birikiminden farklı bir şeydir. Aynı söyleşide Han, "Bugün bilgi birikimi bile ortadan kalkmış durumda" diye yanıtlar, "bunun yerine sadece bilgi var. [Oysa] bilmek bilgiden tamamen farklı bir olgu" (07.01.2020). Açıkça görüldüğü üzere, Han bilmeyi bilgiden ayırmakta, bilmeye bilgiden daha üstün bir statü bahşetmektedir. Bu, aynı zamanda bilgi ile tecrübe arasındaki temel farktır. Bilgi, hele de dijital verilerden hareketle oluşturulmuş nicel bilgi, yaşamın içinden devşirilmediği ve belli bir yaşanmışlık duygusu içermediği sürece tecrübeye yataklık edemez. Han, burada, manidar biçimde bilginin dosyalarda, tecrübeninse zihinde biriktirildiğini iddia eden kaynağı muteber görüşü yankılamaktadır. Han'ın endişesinin nedeni, sadece ihtiva ettiği hızdan dolayı bilginin doğruluğuna duyulan güvensizlik değildir, aynı zamanda dijital bilginin her şeyi tanımlayıcı meşruiyetidir. Başka bir deyişle, asıl endişesi duyulması gereken şey, "her şeyin otomatiğe geçtiği ve algoritmalarla yönetildiği yerde hayatın tehlikeye düşmesidir" (Han, 07.01.2020). Aynı nedenle, verinin, özellikle de büyük veri anlatısının insan yaşamını getirdiği içler acısı durum ortadadır. Neoliberal ideolojinin psikopolitik etkilerinin yaşamın her alanını zapturapt altına almış egemenliğine görünmez bağlarla tabi kılınmış olan bireyler, "şahsın ve özgür iradenin sonunu ilan eden Büyük Veri'nin bir parçasına dönüşmüşlerdir" artık (Bulunmaz, 2019). Bu çıkarıma göre, dijital çağın psikopolitik ideolojisi dikişsiz biçimde her yerdedir; dışarıda bir yerde değil, içselleştirilmiş bir kanaat olarak bizzat bireyin kendi içindedir, hiç kimse bu etkiden muaf değildir. Söz konusu etki bireysel bilinçleri ve öznelliği parçalayıp yok etmekle kalmaz, aynı zamanda tüm parçalı, çok katmanlı ve çok hakikatli yapısı içindeki toplumsal dünyayı da holistik bir bakışın süzgecinden geçirerek matlaştııır. Han'ın durumun vahametine ilişkin 
yaptığı Dadaizm-Dataizm ilişkilendirmesi ise özellikle ilginçtir. Buna göre, dijital bilgiye duyulan saplantılı inanç "bilgi ve veriyi şeffaflaştırırken öznelliği ve özgürlüğü sömürülen kişi de dâhil, her şey 'veri ve enformasyon olabilir' şiarıyla 'dijital totalitarizm'e kapı aralamaktadır" (Bulunmaz, 2019). Her şeyin veri ve enformasyona tercüme edilebilir olması, bilindiği üzere, birinci aydınlanma döneminin her şeyin bilinebilir olduğu/olması gerektiği yanılsamasından kaynaklanır. Her şeyi bilmek, kozmosu insan için bilinebilir kılmak, bilinmeyenin temasını bertaraf etmek, gizemli hiçbir şeye izin vermemek, vb. arayışlar başlangıçta bilumum hurafe hilafına insan aklının özerkliğine yönelik masumane ve haklı bir düşüncenin ürünüydü. Gelgelelim, araçsal aklın hükümranlığını kuran da yine aynı masum ve aymaz düşünce oldu. Bugün gelinen noktada ise, dijital veri hâkimiyetinin yaşamsal hakikati tanımlayıcı tek ölçüt ve norma dönüşmüş olması, daha önceki tüm kavrayış düzlemlerinden daha yıkıcı bir etki yapmaktadır. Bulunmaz'ı izleyerek söylersek (2019); "bu eylem, sayıların ve verilerin mutlaklaştırılıp fetişleştirilmesine kadar ilerletil(miş) ve ardından, nihayetinde kendisini sayılar üzerinden tanıyıp bilmeye çalışan 'niceliksel benliğe' varıl(mış)tır." Dijital ve hesaplanabilir, ölçülebilir veriye yönelik bu saplantıı ilgi, Han'ın niceliksel benlik eleştirisinin de ana kaynağını oluşturur. Aslında nicelenmiş benlik, birey ile bedeni arasında hesaplanabilir bir ilişki olduğu varsayımına şaşmaz bir kesinlikle yeniden işlerlik kazandırırken, onu hislerden ve alışkanlıklardan arındırılmış duygusuz bir makine-varlık olarak konumlandırmaya çalışır. Başka bir deyişle, "niceliksel benlik, neoliberal iktidarın psikopolitikasında önemli bir parça, hatta temel araç olan Büyük Veri'nin, alışkanlıkları kaydetmesini ve iz sürmesini sağlar. Han, buna 'dijital toplu hafızadaki mahkûmiyet' der" (Bulunmaz, 2019). Dijital toplu hafıza, verilerin düşünceyi ve davranışı koşullayıcı, toplumsal dünya gerçekliğini tartışmasız biçimde tanımlatıcı bir mahkûmiyet alanı mıdır gerçekten? Bu soruyu yanıtlamadan önce, söz konusu mahkûmiyete zemin hazırlayan algılama kültürünün hayatın bütünsel gerçekliğini baş döndürücü bir hızla parçalarken anlamını daha da geciktiren etkilerine dair de bir şeyler söylemek yerinde olur.

\section{Dijital Kültür: Hızlanmış Hayat, Gecikmiş Anlam}

Daha önce, bir çalışmamızda Paul Virilio ve "hızlanmış hakikat" izleği üzerinden tartışmaya açmış olduğumuz gibi, hızı enformasyon aktarımı döngüsünde kaygısı duyulması gereken temel şey, toplumsal dünyayı temsil etme araçlarının güvensizliğidir (Köse, 2005, s.230). Dijital iletişim araçları ve genel olarak dijital kültürle birlikte daha da hızlanan ve akışkan hale gelen içerik üretimi, hayatın parçalanmasına koşut olarak, anlamlı yaşama yetisini de büyük ölçüde zedelemiştir. Virilio'nun deyimiyle, bu durum "değişimin dünyasallaşması", var olan gerçekliklerin yüzeyinde hüküm süren "sonlu bir dünyanın içidir" (2003, s.14). Her bakımdan "enformasyon bombası" yla aydınlatımış bu yüzey, hakikate ilişkin bir sıkışmanın yeri olduğu kadar, yine Virilio'nun deyimiyle, "anlık zaman sıkışmasıyla" (2003, s.19) sanal ve parçalanmış bir gerçekliğe odaklanmış yeni bir algılama biçiminin de dolaşıma sokulmasını ifade eder. Dijital kültür çağı, hakikati bakımından parçalanmış, bütünlüğünü yitirmiş bir dünya resmidir. İçeriği 
muazzam ölçekte çoğaltarak "anlamı geciktiren" bir etkiye sahip olan bu kültürün yegâne ayırt edici özelliği, Arslantunalı'nın da deyimiyle, modern zamanların klasik gözetimci simgesel figürü Big Brother'ın yerine, ondan daha aleni ve muteber bir güdümleme biçimi olarak Big Data'yı ikame etmiş olmasıdır (2019, s.132). Hüküm fazlasıyla katı görünebilir, ancak verinin üretici, yaratıcı, problem çözücü, sentezleyici zekânın bir yansıması ya da parçalanmış bir dünyayı bütünleştirici bir tutkal değil de, nicelenmiş benliğin bir aracı ve sürekli dikkat dağıtan bir uyaranlar çokluğu biçiminde kavrandığı yerde, başka türlü düşünmek de olası değildir sanki. Meseleye bu perspektiften bakıldığında, yine Arslantunalı'ya göre "Internet madrabazlarının bize söylemediği şey, internetin bütünlük konusunda hiçbir şey vaat etmeyen büyük bir düzenlenmemiş veri okyanusu olduğudur" (2019, s.133). Dahası, uçsuz bucaksız uzamı ve içeriğinin denetlenemez boyutu bakımından "editörleri ve eleştirmenleri olmayan internet, süzgeçten geçirilmemiş bir veri çöplügüdür" (Arslantunalı, 2019, s.133). İnternet tabanlı dijital çağın önceki kültürel dönemlerden bariz bir farklıı̆ı da, ürettiği içeriklerin çeşitliliği ve sunduğu seçeneklerin çokluğunda göze çarpar. Bu, beşeri ve toplumsal hayatın anlamlı ve bütünlüklü kavranışı açısından öylesine ciddi bir kırılmadır ki, sonunda "post-truth" diye adlandırılan yeni ve oldukça tuhaf bir hakikat tanımlaması bile yaratmıştır. Artık, hakikatler hiç olmadığı kadar akışkan ve değişken, seçenekler daha önce hiç olmadığı kadar sınırsızdır. Seçeneklerin çokluğu, daha önceki çağlarda olduğu gibi, özgürlüklerin bir göstergesi değildir artık, daha ziyade hakikatlerden kaçmanın bariz yollarından birisidir. Bu kaçışın kaçınılmaz sonucu ise, toplumsal dünyada tebarüz eden sonu gelmez bir kakofoni olsa gerektir. Yeniden Arslantunalı'ya kulak verecek olursak, bu "seçenek bolluğunun ve sonsuz seçme hürriyetinin yarattığı tipik davranışlardan biri, okurun, karşısına çıkan rahatsız edici içeriği, görmek duymak istemediğini tek hareketle geri itmesi, oraya hiç uğramadan geçmesidir. [Oysa] eskiden böyle bir imkân yoktu. Basılı gazeteye böyle davranmanız mümkün değildi. Sayfayı katlarken bile görmek istemediğiniz haber gözünüze ilişirdi" (2019, s.153). Her şeyin göz önünde olduğu bir kültürde kaçış da zordur. Seçeneklerin çokluğu ve çeşitliliği, otomatik hızda üretilen içeriklerle birleştiğinde, anlamın gecikmiş bir anlam, düşüncenin de hızlanmış ve yüzeysel nitelikli bir düşünce olması gayet mukadderdir; kuşkusuz, bu sürecin doğal sonucunun "yavaşlık" yönünde yeni bazı arayışları beraberinde getirmesi de: Yavaş gazete, yavaş televizyon, yavaş yemek, yavaş şehir, vb.

Dijital çağın veri üretim hızına koşut biçimde gündeme getirdiği anlam gecikmesi ve deneyim güdüklüğü, toplumsal dünyanın gerçekliğine dair hissiyatın yitirilmesiyle bir arada yürüdüğü içindir ki, aslında bir yönüyle tartışma, her dakika icat edilen yeni araçlar (dijital uygulamalar, alışkanlıklar, tendy'ler, sosyal medya akımları, vb.) ve bunlara uyum sağlama zorunluluğuyla ilgilidir. Başka bir deyişle, konu, sürekli öncelikli kılınmış yeni araçlar eşliğinde bir dizi amaçüreten sistemin akıbetiyle bir arada düşünülmelidir. Bu noktada asıl sorulması gereken soru şudur: Hayata ve toplumsal dünyanın gerçekliğine dair hissiyat bir kez yitirildiğinde, bırakın her yeni icat edilen araçla birlikte bir dizi amaç üreten sistemin akıbetini, bireysel varoluşun selameti için her gün yeniden devşirilmesi zaruri olan yaşama 
gerekçesine ışık tutan o veriyi nereden bulmalıdır? Başka bir şekilde sorarsak, sadece bilgi veren ancak somut bir bilgi birikimine yol açmayan veri yığınlarının yapay ışığıyla aydınlatılmış, ancak kıvrımları yeterince deneyimlenmemiş bir hayat ne ölçüde anlamlı ve değerlidir gerçekten? Eğer yaşamak, bir dizi olay anını fasılalı fasılasız deneyimlemekse, hassaten yaşamakla Baudrillard'cıl anlamda "yaşıyor gibi görünmek" arasındaki o indirgenemez farkı nasıl açıklamalıdır? Dijital kültürün âlimi mutlak veri kudreti bu ve benzeri sorulara ikna edici yanıtlar verebilir mi? Sorun, gerçekten de sadece öznel deneyimin yıkılışı sorunu değil, söz konusu deneyimin cereyan edeceği zeminin de yokluğu sorunudur. Başka bir deyişle, "nedenlerinden kurtulmuş sonuçların virüs hızında yayılmasıyla" (Baudrillard, 2006, s.23) vuku bulan hayati bir anlamsal karmaşa sorunudur. Aşırı imge üretimine koşut olarak beliren anlam kaybı, öznel deneyimin temelini oluşturan her türden duygusal ve hissi temasın yitirilmesiyle doğrudan ilişkilidir. Oysa yazgısı var oluş cezasına çarptırılmış olan faniler için temas etmenin sonu yoktur (Köse, 2019, s.250). Anlamı durmaksızın geciktiren ve hakikati bir türlü vermeyen dijital veri çağında, deneyim, gerçekten de onarılamaz biçimde yıkılmış mıdır? Bu soruya müspet bir yanıt verebilmek her zamankinden daha zordur bugün. Sadece deneyim değil, bazılarına göre, failin kendisi de çoktan yürürlükten kalkmıştır. Kanıtı da şudur ki, ortalık insanın kendi gözlerinden daha güvenilir bulduğu kamera lens ve objektifleri, kulağına kendi çıplak sesinden daha etkileyici gelen yüksek teknoloji ürünü ses efektleri, kendi 'aura'sından bile daha sahici görünen suretlerin kitch görüntüleriyle doludur" (Köse, 2019, s.251). Nitekim bu anlamda Baudrillard'ın düşünce malulü kitle medyası çağına yönelik temel izleği de hemen hemen tüm "göstergelerin boşluğu gösterdiği" bir zelil tefekküre düğümlenir. Buna göre, göstergeler anlam taşıma güçlerinden yoksun olmaları yanında, anlamı tümüyle yok etme gücüne de sahiptirler. Üstelik bunu, anlamı temsil edebilecek yegâne araç olduğu iddiasıyla yaparlar. İmge/görüntü enflasyonu anlam azlığından maluldür ve olgular dünyasına ve beşeri ilişkiler alanına yönelik bir aşinalık veya tanıma değil, yalnızca bir tanımlama getirirler. Dijital çağda insanlar arası ilişkiler de bundan pek farklı değildir. Pettman'ın da vurguladığı gibi, "sözüm ona 'büyük veriler' gerçek bireysel yaşamlara açıklama getirmek için fazlasıyla büyük ölçeklidir ve hiçbir kıymetleri yoktur. Anlamlı tek şey eğridir, sinüs dalgasıdır, örtüşen veri noktalarıdır" (2018, s.70). Verinin büyüklüğünü temsil ettiği şeyin değerine eşitleyen anlayış, yeni tür bir dijital ontoloji yaratmıştır. Bu ontolojinin dikkate aldığı tek şey, veri tabanına kayıtlı olan verilerdir. Buna karşılık, "veri tabanında yer almayan her şey önemsizliğe ve hatta hiçliğe göz kırpmaktadır" (Pettman, 2018, s.87). Göze çarpmadan, iz bırakmadan yaşamanın, görünürlüğü bir kişisel sermaye haline getirmeksizin var olmayı seçmenin peşin cezası, deyim yerindeyse bir hayalet olarak yaşamayı seçmektir. Zira Pettman'ın deyişiyle, "bir 'aramada' çıkmazsan, bizatihi gerçekliğin sorgulanabilir" (2018, s.87). Bu hâkim algılamaya göre, dijital kültür çağının kaçak avcıları envanter kayıtlarında yer almadıklarından, google veya diğer dijital ontoloji platformlarında izi sürülemeyen çağ dışı birer varlık numunesidir. Aynı sorunlu algılama, tanımlanamaz olanı "tanınmaz" olarak kodlar ve bu yaklaşıma asıl kıyıcı niteliğini veren şey, duygusal varlığı köreltici hesaplamalardır. "Tanımak", bir kez "tanımlamak" biçimini aldığında, dijital aklın 
seyri yok sayıcı ontolojiye evrilir. Nihayetinde bir arama motorunda aranıldığında çıkmamak, tanımlanamayan bir nesne olmaktır ve internetin ara yüzeyindekilerle temas edilemeyecek bir mesafede durmak da tekinsiz olana kapı aralamak için yeterlidir. Denebilir ki, yeni dijital ontolojinin yaşamın indirgenemez çoğulluğu hilafına dikkate aldığı şey, pozitif nitelikli nicel bilgidir. Henri Lefebvre de "bilmek artık kavramlar kullanmak değil, sadece enformasyonu almak ve belleğe kaydetmektir" derken (akt. Pettman, 2018, s.111), benzer bir tanıma/tanımlama çelişkisinin altını çizmektedir. Lefebvre devam eder: "Bilmenin yerini alan enformasyon, düşünceyi ortadan kaldırır ve pozitif bilgiyi yaşantının dışında kalan, yığılan, biriken, unutulmadan belleğe kaydedilen şeye indirger" (akt. Pettman, 2018, s.111).

Dijital bilginin tek umudu, otoriter bir teknokrasi yaratmak olmamalıdır. Neil Postman'ın, tüm kültürel yaşam formlarını teknolojinin egemenliğine tabi kılan Teknopoli kavramsallaştırması ve aynı adı taşıyan ünlü yapıtı da "hayatlarımızı bilgiye erişme arayışıyla geçirmeye teşvik edildiğimiz" bir dünyayı anlatır (2006, s.76). Postman, bilgi teknolojilerinin gelişiminden yana hayli kederlidir; zira "manadan yoksun, bilgiden yana mustarip" (Postman, 2006, s.85) bir kültürün yeşerdiğini görmek, başlangıçta verilmiş olan sözlerin -daha çok aydınlanma, daha çok eşitlik, bilgiye aracısız erişim, maksimum özgürlük, vs.- tutulmadığının teyidi gibidir. Bu bağlamda, "teknolojinin geliştiği ortamda bilgi ve insan arasındaki bağın koptuğunu" belirten Postman (2006, s.84); sonunda "kendimizi bilgiyle tüketen bir kültürüz" diye de ekler (2006, s.85). Yazarın bilgi teknolojilerinin hızlı gelişimi karşısında duyduğu endişe, Baudrillard'vari bir bedbinlikle yakından akrabadır. Postman'ın da eleştirisi özünde "mana malulü, bilgi meşgulü" teknolojik bir çağın açmazlarına yöneliktir. Postman'a göre, hızlı mesaj aktarımına bağlı olarak körelen deneyim ufku, çok geçmeden, beraberinde "ruhsal sükûnetin ve toplumsal amaçların çöküşünü" getirir (2006, s.88). Kontrol edilemez boyutlardaki enformasyon akışı ve miktarı karşısında etkili düşünsel bir direnç gösterme gücünden yoksun birey, "savunmasızca tecrübe ettikleri şeylerde anlam bulamaz" (Postman, 2006, s.88). Bilgi ya da enformasyon teknolojilerinin, anlam aktarımı adına uyarıcı bir işlev gördükleri muhakkaktır. Ancak aktardığı içeriğin açık-seçik, anlaşılır, standardize edilebilir, nesnelleştirilebilir ve ölçülebilir olması gerektiği inancı, paradoksal biçimde, tahayyül gücünün kendi üzerine kapanışıyla sonuçlanır. Eldeki yığınla veri ve bilgi biçimi sosyal süreçler hakkında oldukça açıklayıcı ve tartışmasız biçimde doğrudur; gelgelelim, yaratıcı düşünceye ve tahayyül gücüne de bir o kadar karşıttır. Eldeki veriden hareketle modeller, kuramlar, bağlantılar, araştırma desenleri/ tasarımları hazırlanabilir; bu tür amaçlar için oldukça elverişlidir, ancak "makineler karmaşıklığa, şüpheye, belirsizliğe son verdiklerinden" filozofların "hareket nedir?", "zekâ nedir?", "iyi bir yaşam nedir?", vb. sorularına yanıt vermekten de acizdir (Postman, 2006, s.111). Postman, sorgulamayı daha da ileri götürerek bilgisayar teknolojisiyle birlikte "aklın pudrası" (2006: 135) haline gelerek belirgin ölçüde "hafiflemiş" bilginin en temel ve hayati meselelerin çözümünde telkin ettiği güvensizliği gözler önüne serer. "En ciddi problemlerimiz" diye yazar Postman, "ne teknik şeylerdir, ne de bilgi yetersizliğinden kaynaklanır. Eğer bir nükleer felaket gerçekleşecekse" ya da "insanlar açlıktan ölüyorlarsa, bunların nedeni 
yetersiz bilgi değildir" (2006, s.138). Postman'ın dikkati, belirsizliğe alerjisi olan Francis Galton gibi marazi mucitlere kaydığında ise, artık bilginin kendisi güvensizliğin kaynağı değil, bizzat hayatın çoğul hakikatine karşı bir komploya dönüşür. Galton'un İngiliz adalarının ayrıntıı bir güzellik haritasını çıkarması, can sıkıntısını ölçmek için bir yöntem geliştirmeye yeltenmesi, hatta 1884'te kurduğu bir laboratuvar sayesinde üç peni karşılığında insanların kafataslarını ölçme girişimi gibi örneklerden yola çıkarak istatistiksel nesnellik fikrinin tarihsel süreçte kat ettiği mesafenin izini sürer (2006, s.147-163). Son olarak, Postman, Teknopoli'deki sembol selinin kritiğine yönelerek, toplumsal açıdan önemli ahlaksal ve kültürel değerleri erozyona uğratan reklamcılık retoriğini mercek altına alır. Yazarın burada da endişeyle gözlemlediği şey, reklamcılığın amacına varmak için ilahi/dini diskurdan evrensel stereotiplere, anlam ve önemini milli bağlamlardan alan sembollerin "güçsüz düşürülmesinden" (2006, s.188) ulu orta müstehcenliğe ve gizli/aleni nefret söylemlerine varıncaya kadar (2006, s.190) birçok yolu kendine mubah sayan oportünist stratejisinin ürkütücü yüzüdür.

Postman'ın teknolojik egemenliğin inşa ettiği sorunlu ahlaksal boyut hakkında duyduğu kaygılar, dijital kültüre kutsallık mührünü vuran büyük veri kavramı için de geçerlidir. Büyük veri anlatısını büyük bir ümidi açığa vuran bir olgu olarak kavrayanlara göre, kavram gerçekten de "yaşamı, çalışma ve düşünme biçimimizi yeniden şekillendirmeye hazır" yeni bir paradigma oluşturmuştur (Lewis ve Westlund, 2017, s.156). Büyük veri, her şeyden önce büyük bir veri patlamasıdır ve sadece medya ve gazetecilik alanını değil, teknolojik, siyasal, sosyal, kültürel, ekonomik, vb. birçok alandaki mevcut değer ve pratikleri, iş yapma biçimlerini dönüştüren bariz bir etkiye sahiptir. Verilerin büyüklüğü hakkında endişelenmemizi gerektirecek eleştirel akademik çalışmaların hedefinde duran şeyse, olgunun pazarlama, ikna, uyum, baskı, kontrol, tüketim, yönlendirme, ticari/siyasi etkileme, vb. amaçlarla kullanımaya elverişli yapısıdır (Lewis ve Westlund, 2017: 158). Özellikle sosyal medya platformlarının politikası ve pazarlama uygulamalarının stratejileri dikkate alındığında, büyük veri anlatısının merkantilist ve ideolojik niteliği kendiliğinden anlaşılacaktır. Aynı şekilde, gazetecilikte toplumsal gerçekliğin yeniden üretimi bağlamında düşünüldüğünde de, bilimsellik, doğruluk ve kesinlik potansiyellerinin açığa vuruluşunun ve genel olarak nicel yönelişin bir kanıtını sunsa bile, "herhangi bir veri gibi, büyük veri de nesnel gerçekliği temsil etmez" (Lewis ve Westlund, 2017, s.164). Zira veri her ne kadar bilgisayar destekli endüstrilerin vazgeçilmez unsurlarından biriyse de, "var olanın biliminin bir vekili olarak değil, daha ziyade sayıların çok büyük önem taşıdığı epistemolojik bilginin bir biçimi olarak alınmalıdır" (Lewis ve Westlund, 2017, s.164). Joshua Fairfield ve Hannah Shtein ise, temelde veri anlatısının yol açtığı etik tartışmalara eğilirler. "Büyük Veri, Büyük Problemler: Gazetecilik ve Veri Bilimi Etiğinde Yeni Sorunlar" başlıklı ortak makalelerinde, Fairfield ve Shtein, büyük veri etiğiyle ilgili sorunları "boyut", "kümelenme" ve "enformasyonel zarar" alt başlıkları çerçevesinde tartışırlar. IIlki, büyük veri kümelerinin yararlılıkla olan doğrudan ilgisi ve onayı alınmadan sızdıılan kullanıcı bilgileri açısından sorunludur (2017, s.193-195). Yazarların bu başlık altında işaret ettikleri şey, temelde veri madenciliği uygula- 
malarının, gözetimci bir stratejiyle, özellikle güçsüz konumdaki kitleleri olumsuz etkilemesiyle ilgilidir. Kümelenme olgusu da, tıpkı ilkinde olduğu gibi, özerklik, yararlılık ve adalet meseleleriyle bağlantılıdır (Fairfield ve Shtein, 2017, s.196). Kümelenmiş kullanıcılara ilişkin veriler, büyük ölçüde veriye odaklanmayı gerektirdiği durumlarda, araştırmacıları araştırma deneklerinden uzaklaştırdığı gibi, "veri seti bir araya gelmiş binlerce denekten oluştuğu zaman, herhangi bir deneğin muhtemel endişelerini hissetmek de zordur" (Fairfield ve Shtein, 2017, s.196). Kümelenmiş verinin neden olduğu asıl adaletsizlik, her zaman kümelenmiş veriye erişim eşitliğinin olmamasıdır: Başka bir deyişle, verilerin işleniş̧i, depolanması ve yayılması için gerekli olan teknik kapasite ve alt yapının kullanıcılar arasında eşit dağıtılmamış olması... Enformasyonel zarara gelince; bu, araştırma sürecinde araştırma etiği kurallarının sağlanamaması durumudur. Anonimleştirmenin "başarısız bir koruma" sağladığı durumlarda bireysel zarar kaçınılmazdır. Genellikle de son yıllarda anonimleştirmenin başarısız bir koruma olduğuna dair inanç güçlenmektedir. Sözgelimi bir deneğin arama geçmişi, sosyal medya iletileri ya da bağlantıları, tıpkı adını söylemesi gibi, kolaylıkla onun kim olduğunu söyleyebilmektedir" (Fairfield ve Shtein, 2017, s.199). Bu ise, özel ve kişisel bilgilerin izinsizce derlenip kullanılması sorununu, başka bir deyişle, ciddi etik tartışmaları beraberinde getirmektedir. Özellikle Facebook veya Twitter gibi sosyal medya ortamlarından koparılan verilerle, kendisi hakkında veri toplandığından habersiz kişilerin mahremiyetlerinin riske atılması bunun somut bir örneğidir. Dolayısıyla veri bilimi etiği açısından öncelikle hesap verebilirliğin önemi büyüktür. Enformasyonel zararın en aza indirilmesinde gazetecilik etiği ve sosyal bilim etiğine büyük işler düşmektedir. Öte yandan, yine sosyal medya platformları üzerine yapılan çalışmalarda, katılımcı yöntemi merkeze alan "karma yöntemli araştırmalar" da araştırmacının araştırma deneğine vereceği zararın en aza indirilmesinin diğer önemli yollarından birisi olarak dikkate alınabilir (Fairfiled ve Shtein, 2017; s.200).

Etik ve epistemik sorunlara ilaveten, dijital kültürün sınırlarını genel olarak ekonomik işletmecilik, iş etiği ve pragmatizm temelinde bir tür uyumsuzluk veya çatışma alanı olarak işaretleyen bakış açılarıyla, dijital çağı ortak bir kültürel ütopya olarak tayin eden görüşlere de kısaca göz atmak gerekir. İlk eğilimin dijital kültür savunusunun özellikle ekonomik verimlilik kaygısıyla güdülenmiş çevrelerden gelmesi pek de şaşırtıcı değildir. Bu perspektifte en çok öne çıkan eğilimler, son yıllarda sarsıcı bir "dijital dönüşüm manisine" tanık olduğumuzu savunan, içinde bulunduğumuz çağın Büyük Sayısal Akım'ın doğru yönde ilerlediğini teyit eden ekonomik girişim ve göstergelerle dolu olduğundan dem vuran, sık sık kolektif zekâya vurgu yaparak takım ruhunu teşvik eden yaklaşımlardır (Guggenheim, 2020). Gerçekten de dijital kültür çağının ekonomik gerçeğinin intiva ettiği pragmatizm oldukça belirgindir. İşletmecilik alanında dijital kültür tartışmaları görünürde öylesine ikircikli tavırlara sahne olmaktadır ki, hangi koşullarda olursa olsun, mutlaka yeni olanı "deneme"ye cesaret etme ve "başarısız olma hakkı" nı hoşgörüyle karşılamayı salık veren tevazu dolu telkinlere, "sistematik ve operasyonel iç yenilik yarışmaları" gibi verimlilik arttırıcı yönelimleri teşvik etme eğilimi eşlik etmektedir. Dahası, dijital kültürün yer etmesiyle, buralarda mütevazı bir 
üst yönetim ve yaklaşım liderliğinden "Ters Mentorluk", "Gölge Comex" veya "Çalışan Savunuculuğu", vb. terkiplerde cisimleşen yeni bir iş etiğinin kuruluşların yeni işbirliği biçimlerini harekete geçirmesine ve yaymasına yardımcı olan programlar icra edilmektedir (Guggenheim, 2020). Tüm bu çabaların gözlerden gizlediği asıl hakikatse, Frédéric Cavazza'nın da belirttiği gibi (2018), "webin sadece bir teknoloji olmayıp, trilyon dolarlık bir piyasa gerçeği" nin temsilcisi olduğudur. Yine aynı görüşe göre, bireyin web kodlarını anlama ve farklı dijital kullanımları benimseme yeteneğini temsil eden dijital kültür ve bu kodlarla biçimlenmiş dijital kültürel bilinç, erken yaşlarda edinilmesi gereken bir yeti olup, her şeyden önce "X Kuşağı" açısından ciddi bir sorundur. Kültürel bir gecikmenin başlı başına bir "sorun" olarak tarif edilmesi, dahası bununla da yetinilmeyip mevzunun "dijital borç" (Cavazza, 2018) benzetmesiyle ilişkilendirilmesi gerçekten de oldukça manidardır. Zira 60'lı veya 70'li yıllarda doğanların "dijital okuryazarlık açı̆̆ı" kurbanları olarak kabul edilmelerinin nedeni de, bu çağın değer ve normlarına karşı gösterdikleri bariz dirençtir. Cavazza ve benzerlerinin ağzından, dijital kültür becerisi olarak zikrettikleri davranış biçimlerini -sözgelimi Instagramda bir kampanyayı nasıl kodlayacağınızı veya yapılandıracağınızı bilmek, vs.- işittiğimizde ise, aslında sözü edilen becerilerin pek matah şeyler olmadığını fark etmek oldukça rahatlatıcıdır. Bu teknik beceriler bir yana, aynı perspektiften bakıldığında burada aleni ya da zımni önem arz eden tek şey, nihayetinde internetin elektronik merkantilist doğasının haklı çıkarılışından ibarettir. Nitekim "dijital kültüre geçmenin ilk adımı" şeklinde tarif edilen ve genel kabul görmüş bir yaklaşıma göre de "dijital" tanımlamasını hak eden yegâne "yumuşak beceri" ve davranışlar da bunun apaçık birer teyidi gibidir. Buna göre, kimi ufak tefek zorluklarının yanı sıra, "profesyonel bir ortamda dijital kültür, çeviklik, yenilikçilik, müşteri odaklı vizyon, işbirliği, şeffaflık gibi belirli sayıda yumuşak beceri ve davranışların kazanılmasını içerir" (Cavazza, 2018). Mesele, sadece sıralanan bu yumuşak beceri ve davranışları edinmekten ibaret olsa iyidir, dahası da vardır; dijital kültürün herkesi birleştirici norm ve kaidelerinden ilham alacak bir tür dijital ütopya kapıdadır. Başka bir deyişle, dijital kültürel bilinç kazanımının evrensel nitelikli ortak bir kültürün yaratılmasının ön koşullarından biri olduğuna inananların sayısı bir hayli fazladır. Niçin ortak bir dijital kültürün gerekli olduğuna ilişkin üretilen gerekçeler ve bu konuda sorulmuş sorulara verilen ekonomik, politik ve hümanist yanıtlar bunun açık kanıtlarıdır. Sözgelimi Fransa menşeili "siecledigital.fr" internet sitesinin söz konusu soruyla ilgili gerekçe ve yanıtları şu şekildedir: Ortak bir dijital kültüre intiyaç vardır, çünkü toplumların endüstrinin yatırımlarını telafi etmek ve kâr elde etmek için ürettiği teknolojileri nasıl kullanacağını bilmesi şarttır. Aksi halde, muazzam ölçekli potansiyel tüketici rezervuarlarını gereği gibi değerlendirememe riski vardır. İkinci olarak, ortak dijital kültürel bir zeminin yaratılması gerekir, çünkü küreselleşmiş bir dünyada, dijital teknolojilere hâkimiyetin uluslara sağladığı rekabet avantajı bir yana, herhangi bir gelişmiş veya gelişmekte olan ülkenin, teknolojik yeniliğin bu temel ve birleştirici yönünü inmal etmesine olanak yoktur. Bu bağlamda sözgelimi cihaz ergonomisi, ağ verimliliği, bilgi işlem ve depolama kapasiteleri, yapay zekâ, büyük veri veya siber suçlara karşı koruma gibi faaliyetlerin ulus-üstü ölçekli hale gelmesi kaçınılmazdır. Bu ise, tahmin edileceği üzere, iyimser bir düşünce ve 
beklentiyle, uluslar ve toplumlar arasında kendiliğinden politik bir yakınlaşmanın tohumlarını serpecektir. Burada her ne kadar açıkça telaffuz edilmese de, ortak dijital kültürden anlaşılan, aslında yeni iletişim teknolojilerinin gitgide politikadan arındııımış bölgeler ve alanlar yarattığı/yaratacağı varsayımıdır. Üretilen gerekçelerin hümanist boyutuna gelince, ortak bir dijital kültürel duyarlık zeminine ihtiyaç vardır; çünkü dijital iletişim teknolojisi süreç içinde geliştikçe bariz biçimde bir bilgi ve know-how kaybına (filozof Bernard Stiegler tarafından tanımlandığı biçimiyle bir tür proleterleşmeye) yol açacaktır. Bu ise, kaçınılmaz biçimde kendilerini varoIuşsal açıdan anlam kaybına uğrama riski altında hisseden yurttaşların "yeniden güçlendirilmesini" gerektirmektedir; özellikle de geleceğin, ekonomik üreticilere ve onların çığırtkan lobilerine değil de, insanlara emanet edilmesi gerektiğini vaaz eden demokratik toplumlar bağlamında, yurttaşların hem sürekli gelişen dijital teknolojilerle tanışıklık ilişkisi içinde olmaları, hem de bu teknolojilerin öncülük ettiği yeni toplumsal seçimler karşısında ayırt etme güdülerini nasıl kullanacaklarını bilebilmeleri açısından (https://siecledigital.fr, 25.01.2020).

\section{Sonuç}

Sonuç olarak, dijital kültürün temelini oluşturan dijital veri/dijital gerçeklik kavramları, yeni bir ontolojik referans çerçevesi yaratmışıı. Aynı referans çerçevesi, gerek sosyal ve beşeri yaşamda gerekse sosyal bilimler etiği alanında önemli tartışmaları da beraberinde getirmiştir. Teknolojik aklın tüm toplumsal süreçleri tanımlayıcı ve kültürel değerler alanını biçimlendirici etkisini, 2010'lu yıllardan itibaren yeni iletişim ve bilgi teknolojilerinin de giderek yaygınlaşmasıyla daha da kuşatıcı hale gelmeye başlayan dijital kültürel belirlenim almış, bu durum da kaçınılmaz olarak mevcut bilgi/anlam/deneyim kavramlarının tanımlarını değiştirmiştir. Dijital veri/ dijital gerçeklik ve bilgi/anlam ilişkisi bu yeni kültürel algılama ve deneyim döneminin en tartışmalı meseleleridir. Mesele, bir yönüyle de dijital/nicel veri ve gerçeklik algılamasının beşeri ve kültürel deneyimi yansıtıp yansıtamayacağı, temsil edip edemeyeceği tartışmasıdır. Temel varsayım şudur: İstatistiksel değerlendirmelerin temel açmazı, nitel birikim yasasını kuşatacak derinlikte olmamasıdır, zira nasıl ki istatistik, modern zamanlarla birlikte yaşamdan mitolojik boyutu kovmuş ve yeraltına itmişse, dijital verinin yaşamsal gerçekliği nicel yoldan tanımlayıcı gücü de hayatın çok boyutlu katmanlarını salt yüzeysel ve uçucu izlenimlerden ibaret kıımıştır. Baudrillard'dan Virilio'ya, Postman'dan Han'a kadar kitle iletişiminin açmazları ve dijital kültür çağının çıktıları üzerine kafa yoran birçok yazar ve düşünürün kimi küçük farklııklarla birlikte az-çok mutabık kaldıkları bir konudur bu. Özellikle de Han'ın dijital kültürün istatistiksel veriyi kutsayan baskın eğilimine karşı çıkarken dile getirdiği "anlam veriye değil, anlatıya dayanır" teşhisi, büyük ölçüde yaşamın anlamsal derinliğini verinin sınırlı gerçekliğinden dışlamakla kalmamakta, aynı zamanda dijital kültür anlatısını bütünlüklü ve derinlikli bir yaşamsal deneyim süreci oluşturma gücünden de feragat ettirmektedir. Zira Han'ın nitel olana nicelin hilafına yol aldıran cümlesinin izleyen bölümü verinin ihtiva ettiği gerçekliğin anlamdan feragatiyle sonuçlandırımaktadır: "Veriler anlam boşluğunu doldurur." Özetle, bugün verinin salt anlamsal boşlukları doldurmayıp yeni ufuklara ve idraklere yol açabilmesi için, dijital 
kültürün egemen gerçekliğinin ve "nicelin egemenliği" nin hayatlarımızda açtığı derin boşlukları ve yarattığı hissiyat eksilmesini de dikkate alarak, bilgiyi, bilmeyi, duymayı, anlamayı, yaşamsal deneyim ve gerçekliği farklı bir epistemolojik yaklaşım çerçevesinde yeniden düşünmek gerekmektedir.

\section{Kaynakça}

Arslantunalı, M. (2019). Teknopolis: Akıllı Makineler, Dağınık Zihinler. İstanbul: Illetişim Yayınları.

Baudrillard, J. (2005). Simülakrlar ve Simülasyon. (Oğuz Adanır, Çev.). Ankara: Doğu Batı Yayınları.

Baudrillard, J. (2006). Cool Anılar V. (Ayşegül Sönmezay, Çev.) İstanbul: Ayrıntı Yayınları.

Baudrillard, J. (2012). İmkânsız Takas. (Ayşegül Sönmezay, Çev.). İstanbul: Ayrıntı Yayınları.

Boyd, D. ve Crawford, K. (2015). Büyük Veri Üzerine Eleştirel Sorular: Kültürel, Teknolojik ve Bilimsel Bir Olgu hakkında Eleştirel Sorgulamalar. (Bilgesu Savcı, Çev.). Folklor/Edebiyat. 83(21), 199-215.

Bulunmaz, A.(2019). Dijital Totalitarizmin Kıskacında. Erişim 10 Aralık 2019, https://www.kulturservisi.com.

Cabedoche, B. (2019). Médias sociaux, technologies de l'information et de la communication et changement social: des jeux croisés d'acteurs, contrariant toute lecture déterministe portée par les médias, Erişim 20.03.2020, https://hal. archives-ouvertes. fr/hal-02021641.

Cavazza, F. (2018). La culture numérique est le principal facteur de fracture numérique. Erişim 18 Aralık 2019, https://www.sysk.fr/2018/08/28/culture-numerique-fracture-numerique/

Doray, P. et Millerand, F. (2019). Déterminisme technologique in Sciences, technologies et sociétés de A à Z, Frédéric Bouchard, Pierre Doray et Julien Prud'homme (dir.) Montréal: Presses de I'Université de Montréal. pp. 65-69.

Ertürk, N. E. (2018). Dijital Varoluş: Dijitalin Soykütüğüne Doğru. Doğu Batı. Ağustos-Eylül-Ekim, 86: 157-171.

Fairfield, J. ve Shtein, H. (2017). Büyük Veri, Büyük Problemler: Gazetecilik ve Veri Bilimi Etiğinde Yeni Sorunlar. Yeni Medya ve Gazeteciliğin Geleceği içinde. ss.184-206, (Himmet Hülür-Cem Yaşın, Editörler). Ankara: Ütopya Yayıncılık.

Gasset, O. y (2018). Quijote Üzerine Düşünceler. (Mehmet Sait Şener, Çev.). İstanbul: Yapı Kredi Yayınları.

Guénon, R. (2012). Nicelin Egemenliği ve Çağın Alametleri. (Mahmut Kanık, Çev.). İstanbul: İz Yayıncılık. 
Guggenheim, I. (2020). La transformation digitale n'existe pas, il s'agit d'une transformation culturelle dans un monde digital. Erişim 27 Ocak 2020, https:// www.blogdumoderateur.com/imf19-transformation-digitale/

Han, B.-C. (2017). Şeffafık Toplumu. (Haluk Barışcan, Çev.). İstanbul: Metis Yayınları.

Han, B.-C. (2018). Güzeli Kurtarmak. (Kadir Filiz, Çev.). İstanbul: İnsan Yayınları.

Han, B.-C. (2019a). Psikopolitika. (Haluk Barışcan, Çev.). İstanbul: Metis Yayınları.

Han, B.-C. (2019b). Zamanın Kokusu. (Şeyda Öztürk, Çev.). İstanbul. Metis Yayınları.

Han, B.-C. (2020). Bilgi Birikimi Tecrübeden Gelir, Bizlerse Bugün Amatörlüğün Korkusuyla Yaşıyoruz. Han ile söyleşi, Söyleşenler: Niels Boeing \& Andreas Lebert, (Ayşe Serra Kolcu, Çev.). Erişim 7 Ocak 2020, https://www.cins.com.tr.

Kane, O. (2019). Marshall McLuhan et la théorie médiatique: genèse, pertinence et limites d'une contribution contestée, tic \& société, Vol. 10, № 1 I 1er semestre 2016, Erişim 19.03.2020, URL: http://journals.openedition.org/ticetsociete/2043.

Köse, H. (2005). Virilio ve Hızlandırılmış Hakikat. Yeni Düşünceler. 1:229-238.

Köse, H. (2019). Post-Gerçeklik Toplumunda Kamu Yararı: Baudrillard Etkisi Ekseninde Bir İrdeleme. Kamusuz Yararlar Ülkesi: Sağ Popülist Siyaset Çağında Medya ve Kamu Yararı İlkesi içinde, ss.237-276, (Hüseyin Köse, Ed.), Ankara: Ütopya Yayınevi.

Kundera, M. (2019). Yavaşlık. (Özdemir İnce, Çev.). İstanbul: Can Yayınları.

Lejeune, M. (2015). L'apport de la sociologie de la technologie à la professionnalisation de l'ingénieur. Phronesis, 4 (2), 34-41. Erişim 12.03.2002, https://doi. org/10.7202/1033448ar.

Lewis, S. C ve Westlund, O. (2017). Büyük Veri ve Gazetecilik: Epistemoloji, Uzmanlık, Ekonomi ve Etik. Yeni Medya ve Gazeteciliğin Geleceği içinde, ss.155183, (Himmet Hülür-Cem Yaşın, Editörler). Ankara: Ütopya Yayıncılık.

Le numérique en culture. Erişim 25.01.2020, https://siecledigital.fr/2016/09/26/ le-numerique-en-culture/

Pettman, D. (2018). Sonsuz Dikkat Dağınıkığı. (Yunus Çetin, Çev.). İstanbul: Sel Yayıncilik.

Postman, N. (2006). Teknopoli. (Mustafa Emre Yılmaz, Çev.). İstanbul: Paradigma Yayıncilık.

Tinel, B. (2019). Remarques à propos du déterminisme technique, Erişim 18.02.2020, http://halshs.archives-ouvertes.fr/halshs-00196377.

Virilio, P. (2003). Enformasyon Bombası. (Kaya Şahin, Çev.). İstanbul: Metis Yayınları. 